\title{
A novel non-invasive method to detect excessively high respiratory effort and dynamic transpulmonary driving pressure during mechanical ventilation
}

\author{
Michele Bertoni ${ }^{1,2}$, Irene Telias ${ }^{3,4}$, Martin Urner ${ }^{3,5}$, Michael Long ${ }^{6}$, Lorenzo Del Sorbo ${ }^{3,5}$, Eddy Fan ${ }^{3,5,7}$, \\ Christer Sinderby ${ }^{3,4}$, Jennifer Beck ${ }^{3,4}$, Ling Liü ${ }^{8}$, Haibo Qiu' ${ }^{8}$, Jenna Wong ${ }^{5}$, Arthur S. Slutsky ${ }^{3,4}$, \\ Niall D. Ferguson ${ }^{3,5,7,9,10}$, Laurent J. Brochard ${ }^{3,4}$ and Ewan C. Goligher ${ }^{3,5,10,11^{*}}$ (D)
}

\begin{abstract}
Background: Excessive respiratory muscle effort during mechanical ventilation may cause patient self-inflicted lung injury and load-induced diaphragm myotrauma, but there are no non-invasive methods to reliably detect elevated transpulmonary driving pressure and elevated respiratory muscle effort during assisted ventilation. We hypothesized that the swing in airway pressure generated by respiratory muscle effort under assisted ventilation when the airway is briefly occluded $\left(\Delta P_{\text {occ }}\right)$ could be used as a highly feasible non-invasive technique to screen for these conditions.

Methods: Respiratory muscle pressure $\left(P_{\text {mus }}\right)$, dynamic transpulmonary driving pressure $\left(\Delta P_{\mathrm{L}, \text { dyn, }}\right.$ the difference between peak and end-expiratory transpulmonary pressure), and $\Delta P_{\text {occ }}$ were measured daily in mechanically ventilated patients in two ICUs in Toronto, Canada. A conversion factor to predict $\Delta P_{\mathrm{L} \text {,dyn }}$ and $P_{\text {mus }}$ from $\Delta P_{\text {occ }}$ was derived and validated using cross-validation. External validity was assessed in an independent cohort (Nanjing, (China).

Results: Fifty-two daily recordings were collected in 16 patients. In this sample, $P_{\text {mus }}$ and $\Delta P_{L}$ were frequently excessively high: $P_{\text {mus }}$ exceeded $10 \mathrm{~cm} \mathrm{H}_{2} \mathrm{O}$ on $84 \%$ of study days and $\Delta P_{L, \text { dyn }}$ exceeded $15 \mathrm{~cm} \mathrm{H}_{2} \mathrm{O}$ on $53 \%$ of study days. $\Delta P_{\text {occ }}$ measurements accurately detected $P_{\text {mus }}>10 \mathrm{~cm} \mathrm{H}_{2} \mathrm{O}$ (AUROC $0.92,95 \% \mathrm{Cl} 0.83-0.97$ ) and $\Delta P_{\mathrm{L}, \mathrm{dyn}}>15 \mathrm{~cm} \mathrm{H}_{2} \mathrm{O}$ (AUROC 0.93, 95\% Cl 0.86-0.99). In the external validation cohort $(n=12)$, estimating $P_{\text {mus }}$ and $\Delta P_{L, d y n}$ from $\Delta P_{\text {occ }}$ measurements detected excessively high $P_{\text {mus }}$ and $\Delta P_{L, d y n}$ with similar accuracy (AUROC $\geq 0.94$ ). Conclusions: Measuring $\Delta P_{\text {occ }}$ enables accurate non-invasive detection of elevated respiratory muscle pressure and transpulmonary driving pressure. Excessive respiratory effort and transpulmonary driving pressure may be frequent in spontaneously breathing ventilated patients.
\end{abstract}

Keywords: Mechanical ventilation, Artificial respiration, Acute lung injury, Myotrauma, Respiratory monitoring

\footnotetext{
* Correspondence: ewan.goligher@utoronto.ca

${ }^{3}$ Interdepartmental Division of Critical Care Medicine, University of Toronto,

Toronto, Canada

${ }^{5}$ Division of Respirology, Department of Medicine, University Health Network

and University of Toronto, Toronto, Canada

Full list of author information is available at the end of the article
}

(c) The Author(s). 2019 Open Access This article is distributed under the terms of the Creative Commons Attribution 4.0 International License (http://creativecommons.org/licenses/by/4.0/), which permits unrestricted use, distribution, and reproduction in any medium, provided you give appropriate credit to the original author(s) and the source, provide a link to the Creative Commons license, and indicate if changes were made. The Creative Commons Public Domain Dedication waiver (http://creativecommons.org/publicdomain/zero/1.0/) applies to the data made available in this article, unless otherwise stated. 


\section{Introduction}

Patient inspiratory effort during mechanical ventilation may have both beneficial and deleterious effects. Inspiratory effort increases tidal volume and global dynamic lung stress (quantified by transpulmonary driving pressure, $\Delta P_{\mathrm{L}}$ ) in pressure-targeted modes of ventilation, potentially leading to lung injury. Vigorous inspiratory efforts can generate pendelluft and amplify regional lung stress and strain, causing regional lung injury even in volume-cycled modes of ventilation $[1,2]$. The amplitude of this regional stress is reflected by the dynamic transpulmonary driving pressure, $\Delta P_{\mathrm{L} \text {,dyn }}$ [3]. Excess diaphragmatic loading may impair systemic oxygen delivery and cause diaphragm muscle injury $[4,5]$. The level of inspiratory effort during the first 3 days of ventilation was recently shown to predict the duration of ventilation and ICU admission [6]. Respiratory drive and effort are frequently elevated in patients with respiratory failure because of pain, anxiety, delirium, inadequate ventilatory assistance, and dyspnea $[7,8]$. Therefore, patient inspiratory effort merits close attention during mechanical ventilation.

Inspiratory effort (quantified by respiratory muscle pressure, $\left.P_{\text {mus }}\right)$ is not routinely monitored during mechanical ventilation. Although several monitoring techniques are available (e.g., esophageal manometry [9], diaphragm electrical activity (Edi) [10], diaphragm ultrasound [11]), they require appropriate equipment, proficiency, and time, making it difficult for busy clinicians to assess inspiratory effort as part of routine respiratory monitoring. $P_{0.1}$ is a simple and widely available method for estimating respiratory drive during mechanical ventilation [12], but it provides little information about the magnitude of dynamic lung stress generated by the combined effects of the ventilator and patient respiratory effort. Plateau pressure and driving pressure are used to detect excess lung stress during controlled mechanical ventilation [13], but these measurements may not be reliable in the presence of inspiratory effort as they can underestimate the true magnitude of stress and strain applied to the lung both globally and regionally [14]. Moreover, these measurements represent the total elastic pressure of the respiratory system (combining the lung and the chest wall); elevated values therefore do not necessarily entail excess lung stress when chest wall elastance is increased. A rapid and non-invasive technique for detecting excess respiratory effort and dynamic lung stress would substantially increase the feasibility of detecting injurious spontaneous breathing during mechanical ventilation.

During a randomly applied end-expiratory airway occlusion on the ventilator, the airway pressure deflection generated by the patient's respiratory effort against the occluded airway $\left(\Delta P_{\text {occ }}\right)$ is correlated with the pressure generated by the respiratory muscles to expand the lungs and chest wall during mechanically assisted breaths because a single end- expiratory occlusion does not alter respiratory drive [15]. Hence, $\Delta P_{\text {occ }}$ may provide a non-invasive means of detecting excessive inspiratory effort and dynamic lung stress during assisted mechanical ventilation.

We hypothesized that excessive patient inspiratory effort $\left(P_{\text {mus }}\right)$ and excessive dynamic lung stress $\left(\Delta P_{\mathrm{L}, \mathrm{dyn}}\right)$ could be detected rapidly and non-invasively by measuring $\Delta P_{\text {occ }}$.

\section{Methods}

This study was conducted in two medical-surgical intensive care units at the University Health Network, Toronto, Canada. The findings presented in this paper represent an ancillary analysis on an ongoing clinical study (MYOTRAUMA, ClinicalTrials.gov NCT03108118) characterizing diaphragm activity and function longitudinally during mechanical ventilation. Informed consent was obtained from substitute decision makers prior to enrolment. If no substitute decision maker was available, eligible patients were enrolled by deferred consent and consent for the use of study data was obtained from study participants once they regained capacity. The Research Ethics Board at University Health Network approved the study protocols, and the study was performed in accordance with the ethical standards laid down in the 2008 Declaration of Helsinki. The study findings were validated in a dataset collected from a previously published cohort of patients in China [16].

\section{Study subjects}

Patients were enrolled in the MYOTRAUMA study if they were intubated for fewer than $36 \mathrm{~h}$ and if the reason for intubation was one of acute brain injury (i.e., stroke or traumatic brain injury), acute respiratory distress syndrome (ARDS), septic shock, or pneumonia. Patients were excluded if they were deemed unlikely to remain on the ventilator for at least 7 days, if there was a contraindication to esophageal catheterization (recent upper GI surgery, bleeding varices), or if they had a concomitant acute exacerbation of obstructive airways disease. Recordings obtained in MYOTRAUMA study subjects were included from days when the subjects were breathing spontaneously (triggering the ventilator).

\section{Study protocol}

Study methods are detailed in an online supplement (see Additional file 1). Flow, airway pressure $\left(P_{\mathrm{aw}}\right)$, esophageal pressure $\left(P_{\mathrm{es}}\right)$, and diaphragm electrical activity $\left(E_{\mathrm{di}}\right)$ were recorded for $10 \mathrm{~min}$ on a daily basis. During each recording, 15-20 expiratory airway occlusions were applied on the Servo-I ventilator (Getinge, Solna, Sweden) at random intervals. Each occlusion was maintained for the duration of a single breath (confirmed by the return of $P_{\mathrm{aw}}$ and $E_{\mathrm{di}}$ to baseline, see Fig. 1). The maximal 


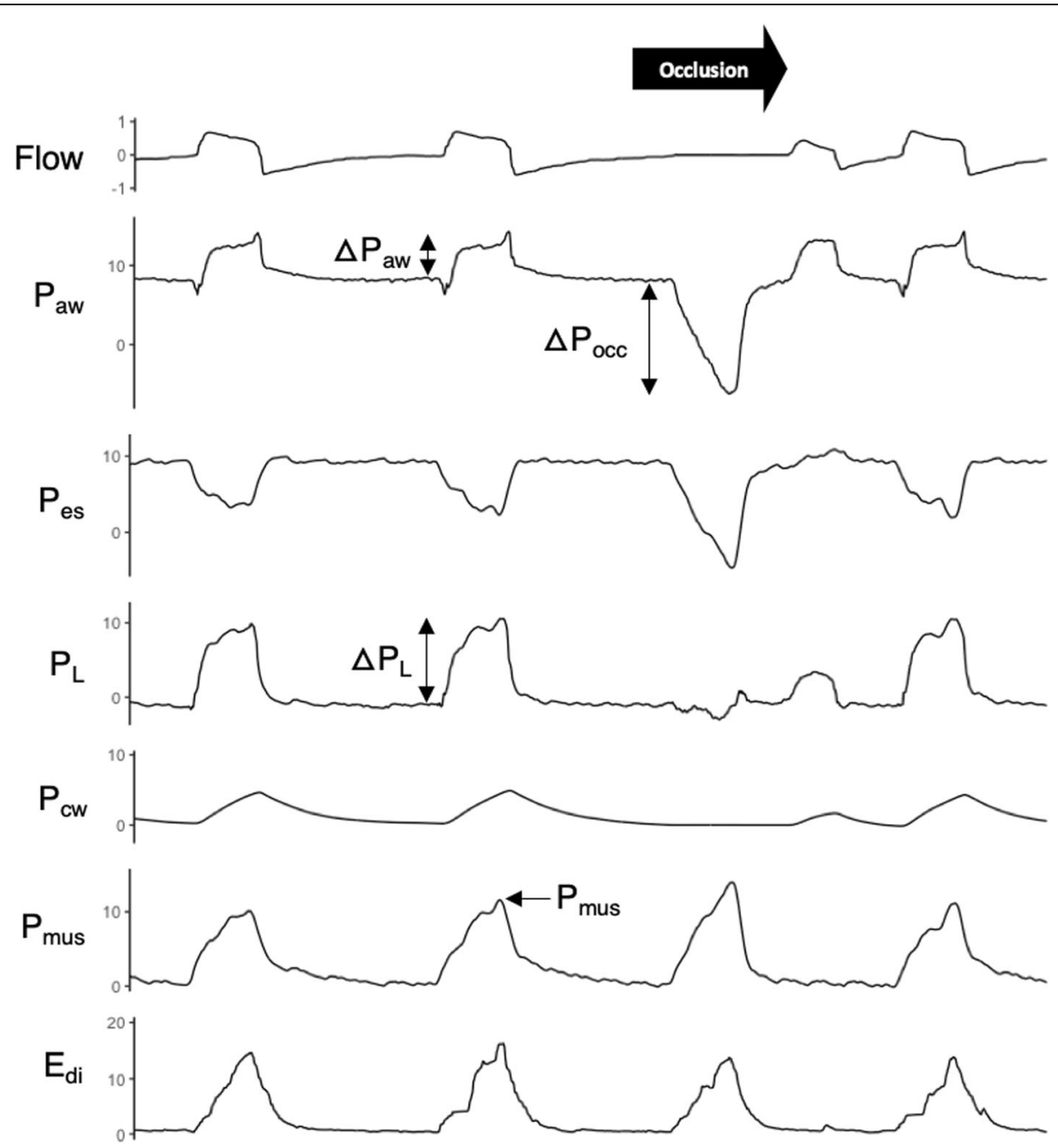

Fig. 1 Representative tracings obtained during the airway occlusion maneuver. Flow, airway pressure $\left(P_{\text {aww }}\right)$, esophageal pressure $\left(P_{\text {es }}\right)$, and diaphragm electrical activity $\left(E_{\mathrm{di}}\right)$ were recorded while a one-way end-expiratory occlusion permitting expiratory flow but not inspiratory flow (black arrow) was applied at a random interval. Transpulmonary pressure $\left(P_{\mathrm{L}}\right)$, obtained by digital subtraction of $P_{\text {es }}$ from $P_{\text {aw, }}$ signifies the dynamic stress applied to the lung. Chest wall elastic recoil pressure $\left(\Delta P_{c w}\right)$ was estimated by multiplying tidal volume by predicted chest wall elastance. Inspiratory effort was quantified by the peak inspiratory muscle pressure, $P_{\text {mus, }}$ estimated as the difference between $\Delta P_{\mathrm{cw}}$ and $\Delta P_{\mathrm{es}}$ (baseline $P_{\text {mus }}$ is $0 \mathrm{~cm} \mathrm{H}_{2} \mathrm{O}$ by definition). Note that peak $E_{\mathrm{di}}$ did not differ between occluded and non-occluded breaths

deflection in $P_{\text {aw }}$ from PEEP during each occlusion was recorded as a measurement of occlusion pressure $\left(\Delta P_{\text {occ }}\right)$ (note: not to be confused with the airway occlusion pressure at 100 milliseconds after the onset of inspiration, $\left.P_{0.1}\right)$.

\section{Signal analysis}

Transpulmonary pressure $\left(P_{\mathrm{L}}\right)$ was measured by real-time digital subtraction of $P_{\mathrm{es}}$ from $P_{\mathrm{aw}}$. The airway driving pressure $\left(\Delta P_{\text {aw,dyn }}\right)$ was quantified as the difference between peak $P_{\text {aw }}$ and PEEP. The dynamic transpulmonary driving pressure $\left(\Delta P_{\mathrm{L}, \mathrm{dyn}}\right)$ was quantified for each breath as the increase in $P_{\mathrm{L}}$ from onset to peak during inspiration. Chest wall elastic recoil pressure at end-inspiration $\left(P_{\mathrm{cw}}\right)$ was estimated for each breath from the product of tidal volume and the empirically estimated chest wall elastance (see Additional file 1, Additional file 2, Additional file 3, Additional file 4, and Additional file 5). The pressure generated by the respiratory muscles during inspiration $\left(P_{\text {mus }}\right)$ (i.e., the pressure that expands the lung and chest wall during inspiration) was quantified for each breath as the peak difference between $P_{\mathrm{cw}}$ and $P_{\mathrm{es}}$ during inspiration. Pressure-time product of $P_{\text {mus }}$ per breath ( $\left(\mathrm{PT}_{\text {mus }}\right)$-the reference standard for quantifying inspiratory effort [17] - was computed from $P_{\mathrm{cw}}$ and the integral of $P_{\mathrm{es}}$ during inspiration (see Additional file 1, Additional file 2, Additional file 3, Additional file 4, and Additional file 5).

To avoid measurement error due to inaccurate $P_{\mathrm{es}}$ measurements, recordings where the ratio of $\Delta P_{\mathrm{occ}} / \Delta P_{\mathrm{es}}$ was greater than 1.3 or less than 0.7 were excluded from analysis. 
Defining excessive $P_{\text {mus }}$ and $\Delta P_{\mathrm{L}}$

Thresholds defining excessive $P_{\text {mus }}$ and $\Delta P_{\mathrm{L} \text {,dyn }}$ were selected a priori based on available physiological and clinical observations (see Additional file 1 for detailed rationale). $P_{\text {mus }}$ normally ranges between 4 and $10 \mathrm{~cm} \mathrm{H}_{2} \mathrm{O}$, and $\Delta P_{\mathrm{L}, \mathrm{dyn}}$ normally ranges between 4 and $8 \mathrm{~cm} \mathrm{H}_{2} \mathrm{O}$ [1820]. Given some uncertainty in the optimal definitions for excessive $P_{\text {mus }}$ and $\Delta P_{\mathrm{L}, \mathrm{dyn}}$, discriminative accuracy was assessed for two different possible definitions of "excessive" values: for $P_{\text {mus }}, 10 \mathrm{~cm} \mathrm{H}_{2} \mathrm{O}$ and $15 \mathrm{~cm} \mathrm{H}_{2} \mathrm{O}$, and for $\Delta P_{\mathrm{L}, \mathrm{dyn}}, 15 \mathrm{~cm} \mathrm{H}_{2} \mathrm{O}$ and $20 \mathrm{~cm} \mathrm{H}_{2} \mathrm{O}$.

\section{Statistical analysis}

The goal of the analysis was to determine whether $\Delta P_{\text {осс }}$ measured during airway occlusions could be used to predict the average values of $\Delta P_{\mathrm{L}, \text { dyn }}$ and $P_{\text {mus }}$ for nonoccluded (assisted) breaths during each daily 10-min recording and to detect when the average values of $\Delta P_{\mathrm{L} \text {,dyn }}$ and $P_{\text {mus }}$ for non-occluded (assisted breaths) exceeded the cut-off values defined above.

For internal validation, we employed a cross-validation procedure (100 repetitions). During each crossvalidation, patients were randomly divided into derivation $(n=10,50 \%)$ and internal validation $(n=10,50 \%)$ cohorts. In the derivation cohort (step 1), the ratios of mean $P_{\text {mus }}$ (during all non-occluded breaths) to the mean $\Delta P_{\text {occ }}\left(k_{1}=P_{\text {mus }} / \Delta P_{\text {occ }}\right)$ and mean $\Delta P_{\text {es }}$ (during all non-occluded breaths $)$ to the mean $\Delta P_{\text {occ }}\left(k_{2}=\Delta P_{\text {es }} /\right.$ $\left.\Delta P_{\text {occ }}\right)$ were computed in each daily recording using linear mixed-effects models to account for repeated recordings within subjects.

In the internal validation cohort (step 2), the derived values of $k_{1}$ and $k_{2}$ were used to predict $P_{\text {mus }}$ and $\Delta P_{\text {es }}$ (and hence $\Delta P_{\mathrm{L}, \mathrm{dyn}}$ as $\Delta P_{\mathrm{aw}}-\Delta P_{\mathrm{es}}$ ) from three randomly selected measurements of $\Delta P_{\text {occ }}$ in each recording (to mimic the use of just three occlusion maneuvers for prediction in clinical practice) according to Eqs. 1 and 2.

$$
\begin{aligned}
& P_{\text {mus }, \text { predicted }}=k_{1} \times \Delta P_{\text {occ }} \\
& \Delta P_{\mathrm{L}, \text { dyn }, \text { predicted }}=\Delta P_{\mathrm{aw}}-k_{2} \times \Delta P_{\mathrm{occ}}
\end{aligned}
$$

Predicted and observed values of $P_{\text {mus }}$ and $\Delta P_{\mathrm{L}, \text { dyn }}$ were compared using Bland-Altman limits of agreement. To account for repeated measures within patients, linear mixedeffects models were employed to estimate within-patient limits of agreement as a proportion of the estimated value (LA $\%$,within $)$ [21]. Values were log-transformed because of non-normality in the distribution of differences between predicted and estimated values [22]. The mean and between-patient standard deviation of the bias between measured and predicted $P_{\text {mus }}$ and $\Delta P_{\mathrm{L}}\left(\mathrm{SD}_{\text {bias,btw }}\right)$ were also computed in linear mixed-effects models. Total limits of agreement for $P_{\text {mus }}$ and $\Delta P_{\mathrm{L}}$ across the range of estimated values were estimated as $1.96 \times \mathrm{SD}_{\text {bias,btw }}+$
LA\%,within $\times$ estimated value. The ability of predicted $P_{\text {mus }}$ and $\Delta P_{\mathrm{L}, \text { dyn }}$ to detect excessive $P_{\text {mus }}$ and $\Delta P_{\mathrm{L} \text {,dyn }}$ (defined by above threshold values) was evaluated in the internal validation cohort by receiver operating characteristic curve analysis and by computing sensitivity and specificity.

The cross-validation procedure (steps 1 and 2) was repeated 100 times to evaluate the stability of validity estimates during repeated random sampling [23]. All statistical analyses were conducted using $\mathrm{R}$ version 3.4 .3 (www.r-project.org).

\section{External validation}

The discriminative validity and sensitivity and specificity of predicted $P_{\text {mus }}$ and $\Delta P_{\mathrm{L}}$ to detect excessive $P_{\text {mus }}$ and $\Delta P_{\mathrm{L}, \text { dyn }}$ were independently quantified in a separate previously published cohort of patients studied in a different center (Nanjing, China) receiving partially assisted ventilation in whom random expiratory airway occlusions were applied at varying levels of ventilator support $(n=13)[16]$.

\section{Results}

\section{Prevalence of excessive respiratory effort and dynamic lung stress}

After excluding 30 recordings because the ratio of $\Delta P_{\text {occ }} / \Delta P_{\text {es }}$ was greater than 1.3 or less than 0.7 , a total of 52 daily recordings were available in 16 subjects (median 3, IQR 2-5 daily recordings per patient); representative tracings are shown in Fig. 1. Twelve patients were available in the external validation cohort. Patient characteristics in both cohorts are summarized in Table 1.

$P_{\text {mus }}$ and $\Delta P_{\mathrm{L}, \text { dyn }}$ during assisted ventilation ranged widely in the cohort (Fig. 2). $P_{\text {mus }}$ exceeded $10 \mathrm{~cm} \mathrm{H}_{2} \mathrm{O}$ on $84 \%$ of patient-days in the study and exceeded 15 $\mathrm{cm} \mathrm{H}_{2} \mathrm{O}$ on $53 \%$ of patient-days. In 14 patients $(88 \%)$, $P_{\text {mus }}$ exceeded $10 \mathrm{~cm} \mathrm{H}_{2} \mathrm{O}$ on at least one study day. There was no evidence of a correlation between $P_{\text {mus }}$ and $\mathrm{pH}(p=0.21)$ or $\mathrm{PaO}_{2}(p=0.57)$. The correlations between $P_{\text {mus }}$ and SAS score $\left(p=0.07, R^{2}=0.06\right)$ and SOFA score $\left(p=0.08, R^{2}=0.09\right)$ did not reach significance. $P_{\text {mus }}$ was inversely correlated with $\mathrm{PaCO}_{2}(p=$ $\left.0.03, R^{2}=0.11\right) . P_{\text {mus }}$ was higher under partially assisted modes (mean difference $8 \mathrm{~cm} \mathrm{H}_{2} \mathrm{O}, p=0.02$ ) and higher in patients admitted for pneumonia compared to patients with non-pulmonary admission diagnoses (mean difference $\left.11 \mathrm{~cm} \mathrm{H} \mathrm{H}_{2} \mathrm{O}, p=0.05\right)$.

$\Delta P_{\mathrm{L} \text {,dyn }}$ exceeded $15 \mathrm{~cm} \mathrm{H}_{2} \mathrm{O}$ on $69 \%$ of patient-days and exceeded $20 \mathrm{~cm} \mathrm{H}_{2} \mathrm{O}$ on $40 \%$ of patient-days. In 13 patients $(81 \%), \Delta P_{\mathrm{L} \text {,dyn }}$ exceeded $15 \mathrm{~cm} \mathrm{H}_{2} \mathrm{O}$ on at least one study day. $\Delta P_{\mathrm{L} \text {,dyn }}$ was generally substantially higher than $\Delta P_{\text {aw }}$ because pleural pressure (represented by $P_{\mathrm{es}}$ ) decreases during inspiration even while $P_{\text {aw }}$ increases (median difference $12 \mathrm{~cm} \mathrm{H}_{2} \mathrm{O}$, IQR $8-18 \mathrm{~cm} \mathrm{H}_{2} \mathrm{O}, p<0.001$ ). 
Table 1 Patient characteristics

\begin{tabular}{|c|c|c|}
\hline Patient characteristic & Primary cohort $(n=16)$ & $\begin{array}{l}\text { External validation cohort } \\
(n=12)\end{array}$ \\
\hline $\mathrm{N}$ measurements in cohort & 52 & 46 \\
\hline$N$ measurements per patient ${ }^{a}$ & $3(2-5)$ & $3(1-7)$ \\
\hline Age (years) (mean, SD) & $63(10)$ & $60(57-73)$ \\
\hline Sex ( $n, \%$ female) & $7(44 \%)$ & 10 (83\%) \\
\hline \multicolumn{3}{|l|}{ Cause of respiratory failure $(n, \%)$} \\
\hline Pneumonia & $10(62 \%)$ & $10(83 \%)$ \\
\hline Non-pulmonary sepsis & $2(13 \%)$ & $0(0 \%)$ \\
\hline Cardiogenic shock & $0(0 \%)$ & $2(17 \%)$ \\
\hline Intracranial hemorrhage & $3(19 \%)$ & $0(0 \%)$ \\
\hline Ischemic stroke & $1(6 \%)$ & $0(0 \%)$ \\
\hline Sedation-Agitation Scale score ${ }^{b}$ & $2(2-3)$ & Not reported \\
\hline Baseline nadir $\mathrm{PaO}_{2} / \mathrm{FiO}_{2}(\mathrm{~mm} \mathrm{Hg})$ & $148(105-173)$ & Not reported \\
\hline \multicolumn{3}{|l|}{ Mode of ventilation ( $n$ days, \%) } \\
\hline Volume assist-control & $1(2 \%)$ & - \\
\hline Pressure assist-control & $9(17 \%)$ & - \\
\hline Pressure support & 39 (75\%) & - \\
\hline Not recorded & $3(6 \%)$ & - \\
\hline Neurally adjusted ventilatory assist & $0(0 \%)$ & $12(100 \%)$ \\
\hline$\Delta P_{\text {aw }}\left(\mathrm{cm} \mathrm{H}_{2} \mathrm{O}\right)^{\mathrm{b}}$ & $5(3-7)$ & $10(9-17)$ \\
\hline$P_{\text {mus }}\left(\mathrm{cm} \mathrm{H}_{2} \mathrm{O}\right)^{\mathrm{b}}$ & $16(12-22)$ & $7(5-9)$ \\
\hline$\Delta P_{\mathrm{L}}\left(\mathrm{cm} \mathrm{H} \mathrm{H}_{2} \mathrm{O}\right)^{\mathrm{b}}$ & $18(14-23)$ & $18(14-22)$ \\
\hline
\end{tabular}

Results are presented as median and interquartile range unless otherwise reported

${ }^{\mathrm{a}}$ In the primary cohort, one measurement was obtained per day; in the external validation cohort, multiple measurements were obtained on the same day at varying NAVA support levels

${ }^{b}$ Values reported include repeated measurements within subjects over different study days

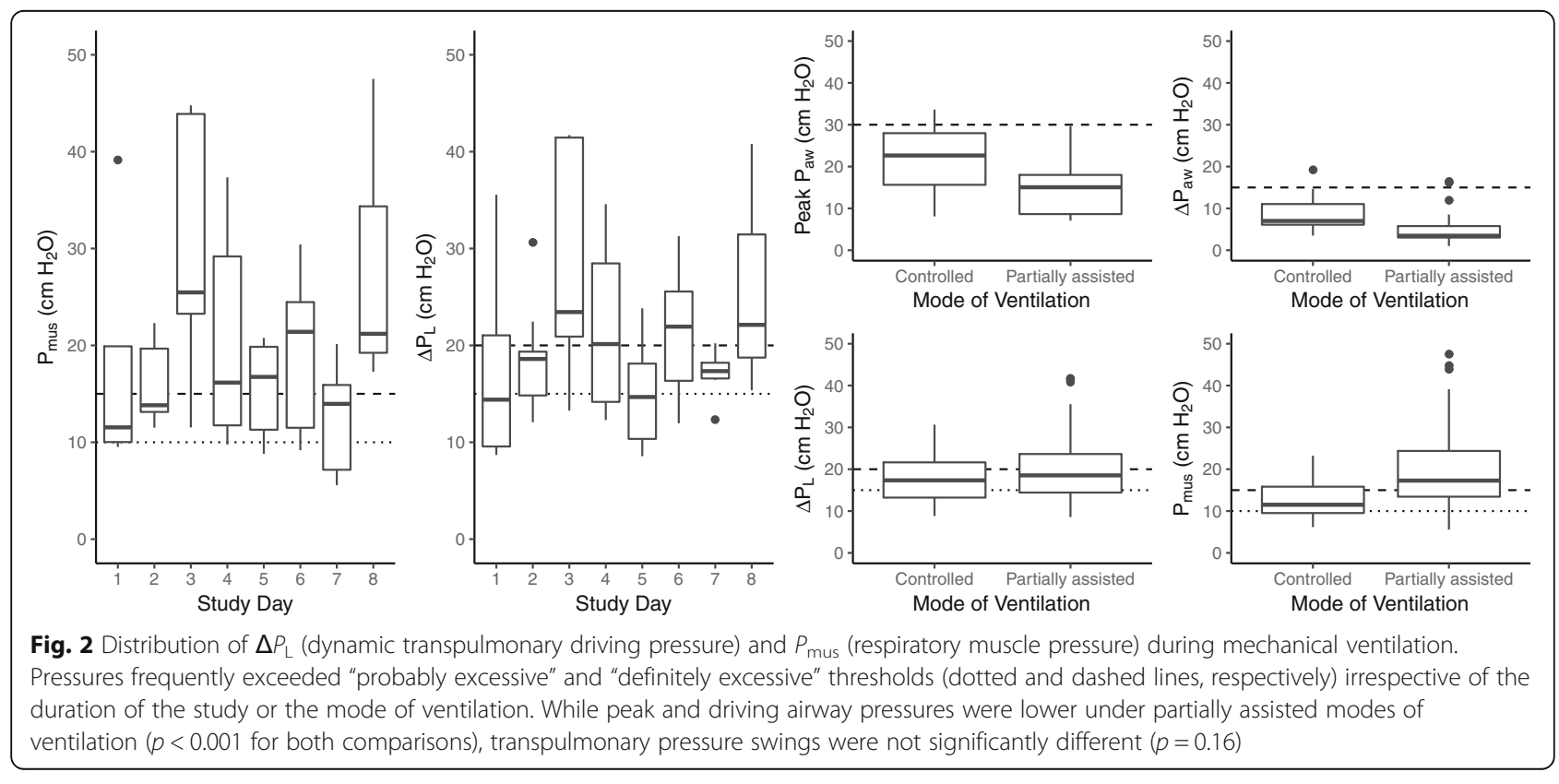


Although peak airway pressure and airway driving pressure were lower on days when patients were ventilated in pressure support ventilation mode compared to volume or pressure-control ventilation $(p<0.005$ for both comparisons), $\Delta P_{\mathrm{L}, \mathrm{dyn}}$ was not significantly different $(p=0.16)$ (Fig. 2). $\Delta P_{\mathrm{L}, \mathrm{dyn}}$ was higher in patients admitted for pneumonia compared to patients with a non-pulmonary diagnosis (mean difference $9 \mathrm{~cm} \mathrm{H}_{2} \mathrm{O}, p=0.05$ ).

$P_{\text {mus }}$ and $\Delta P_{\mathrm{L}, \text { dyn }}$ were both within ideal limits $\left(P_{\text {mus }} \leq\right.$ $10 \mathrm{~cm} \mathrm{H}_{2} \mathrm{O}$ and $\Delta P_{\mathrm{L}, \mathrm{dyn}}<15 \mathrm{~cm} \mathrm{H}_{2} \mathrm{O}$ ) on only $8 \%$ of patient-days.

\section{Validity of $\Delta P_{\text {occ }}$ as a non-invasive marker of respiratory effort}

There was no systematic difference in peak $E_{\mathrm{di}}$ between occluded and non-occluded breaths (mean difference $0 \mu \mathrm{V}$, limits of agreement $\pm 4 \mu \mathrm{V}$ ) confirming that respiratory drive was unaffected by the randomly applied intermittent airway occlusion. $\Delta P_{\text {occ }}$ was highly correlated with $\mathrm{PTP}_{\text {mus }}$ (Additional file 2: Figure S1, betweensubjects $R^{2}=0.71$, within-subjects $R^{2}=0.85$ ).

\section{Detecting excessive $P_{\text {mus }}$ and $\Delta P_{\mathrm{L}}$ from $\Delta P_{\text {occ }}$} In the derivation cohorts, $k_{1}$ (ratio of $P_{\text {mus }} / \Delta P_{\text {occ }}$ ) was $0.74(95 \% \mathrm{CI}-0.69,-0.78)$ and $k_{2}$ (ratio of $\Delta P_{\text {es }} / \Delta P_{\text {occ }}$ ) was $0.66(0.61-0.70)$.

Agreement between predicted and measured values of $P_{\text {mus }}$ and $\Delta P_{\mathrm{L}, \mathrm{dyn}}$ in the internal validation cohorts was marginally acceptable: bias (the magnitude of difference between predicted and measured values) varied between subjects and the within-subject limits of agreement were relatively wide (Additional file 3: Figure S2, Additional file 4: Table S1). Nevertheless, predicted $P_{\text {mus }}$ and $\Delta P_{\mathrm{L}, \mathrm{dyn}}$ accurately detected excessive $P_{\text {mus }}$ and $\Delta P_{\mathrm{L}, \mathrm{dyn}}$ with areas under the receiver operating characteristic curves (AUROC) suggesting strong discriminative performance (AUROC $>0.9$ in all cases, Fig. 3 , Additional file 5: Table S2). Sensitivity and specificity of different cut-off values of predicted $P_{\text {mus }}$ and $\Delta P_{\mathrm{L}, \mathrm{dyn}}$ for excessive measured $P_{\text {mus }}$ and $\Delta P_{\mathrm{L}, \mathrm{dyn}}$ are shown in Additional file 5: Table S2.

Based on the findings in the primary cohort, the utility of $\Delta P_{\text {occ }}$ was tested in the external validation cohort using values of $k_{1}=-3 / 4$ and $k_{2}=2 / 3$. Discriminative performance, sensitivity, and specificity for excessive $P_{\text {mus }}$ and $\Delta P_{\mathrm{L}, \text { dyn }}$ were similarly strong (AUROC $\geq 0.94$ for both excessive $P_{\text {mus }}$ and $\Delta P_{\mathrm{L}, \mathrm{dyn}}$, Additional file 5: Table S2).

\section{Discussion}

We demonstrate for the first time that measurement of $\Delta P_{\text {occ }}$ from three randomly applied end-expiratory occlusion maneuvers can detect excessive $P_{\text {mus }}$ and $\Delta P_{\mathrm{L}, \text { dyn }}$ with high sensitivity and specificity, even though agreement between predicted and measured values are not sufficiently reliable to provide direct estimates of $P_{\text {mus }}$ and $\Delta P_{\mathrm{L}, \mathrm{dyn}}$. Second, we report for the first time that in spontaneously breathing patients under mechanical ventilation, inspiratory effort and dynamic lung stress frequently exceed putative safe thresholds, irrespective of the depth of sedation or mode of ventilation. Patients only infrequently exhibited the "ideal" combination of lung and diaphragm-protective ventilation parameters $\left(P_{\text {mus }} \leq 10 \mathrm{~cm} \mathrm{H}_{2} \mathrm{O}\right.$ and $\left.\Delta P_{\mathrm{L}, \mathrm{dyn}} \leq 15 \mathrm{~cm} \mathrm{H}_{2} \mathrm{O}\right)$. The magnitude of dynamic lung stress during spontaneous breathing was often seriously underestimated by airway pressures available on the ventilator, confirming that airway pressures on the ventilator are an unreliable marker of dynamic lung stress when patients are spontaneously breathing.

Our method relies on predicting the swing in pleural pressure (quantified by $P_{\mathrm{es}}$ ) under dynamic conditions (airway open) from the swing in airway pressure under quasi-static conditions (airway occluded). Under quasistatic conditions, the swing in pleural pressure matches the swing in airway pressure exactly. The swing in pleural pressure is smaller during inspiration than under quasi-static conditions because of the force-velocity relation of muscle and because of differences in chest wall mechanics and thoracoabdominal motion [24, 25]. Despite these sources of heterogeneity, we found that the conversion factors $k_{1}$ and $k_{2}$ for converting quasi-static conditions to dynamic conditions were fairly stable between patients and over time. These conversion factors provide the physiological basis for predicting $P_{\text {mus }}$ and $\Delta P_{\mathrm{L}, \mathrm{dyn}}$ from $\Delta P_{\text {occ. }}$. Of note, a substantial proportion of recordings had to be excluded because $\Delta P_{\text {occ }}$ differed from $\Delta P_{\text {es }}$ during the occlusion maneuver-this highlights the importance of carefully considering esophageal balloon catheter placement when using $P_{\text {es }}$ for monitoring.

\section{Inspiratory effort and dynamic lung stress during assisted mechanical ventilation}

The transition to partially assisted modes of ventilation is often regarded as a sign of recovery and progress towards liberation from the ventilator. However, important new insights about the potential for lung injury due to excessive inspiratory effort and the associated increase in global and regional lung stress (a phenomenon referred to as patient self-inflicted lung injury, P-SILI [26]) motivate efforts to avoid excessive effort and lung stress.

Our data suggest that greater attention should be paid to the potential risks of excessive inspiratory effort and dynamic lung stress during assisted mechanical ventilation. Observed $P_{\text {mus }}$ and $\Delta P_{\mathrm{L}, \mathrm{dyn}}$ frequently exceeded putative safe levels of inspiratory effort and lung stress. Reliable and feasible clinical monitoring systems are essential to ensure safe and effective ventilation. Although clinicians ordinarily rely on plateau, peak, and driving 


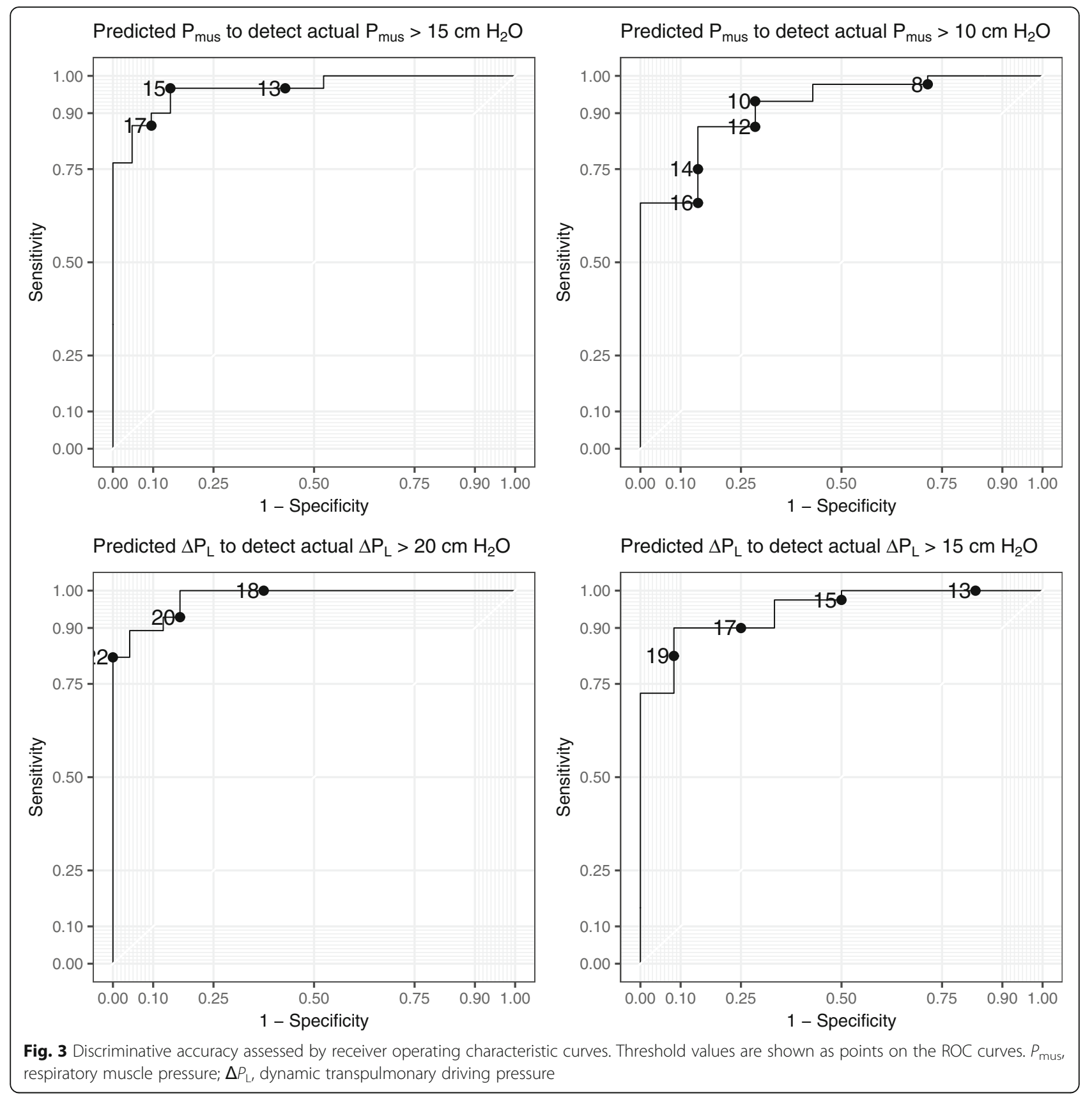

airway pressures, these parameters can seriously underestimate the true magnitude of lung stress during spontaneous breathing due to the negative pleural pressure generated by the respiratory muscles, which is usually not measured. Clinicians should therefore avoid relying on airway pressure measurements alone to assess the safety of mechanical ventilation in spontaneously breathing patients.

Measurement of $\Delta P_{\text {occ }}$ as described for the first time in this study offers a highly feasible and sensitive means of detecting excessive inspiratory effort and dynamic lung stress. It is important to note that $\Delta P_{\mathrm{L}, \mathrm{dyn}}$ can only be predicted if $\Delta P_{\text {occ }}<0 \mathrm{~cm} \mathrm{H}_{2} \mathrm{O}$; when inspiratory effort is absent, the inspiratory swing in $\Delta P_{\text {es }}$ will be positive, and hence, $\Delta P_{\mathrm{L}, \mathrm{dyn}}$ will not be correlated to $\Delta P_{\mathrm{occ}}$.

\section{Limitations}

This study has several limitations. First, $P_{\text {mus }}$ and $\Delta \mathrm{P}_{\mathrm{L}, \mathrm{dyn}}$ were estimated from measurements of airway and esophageal pressure. Due to the presence of active inspiratory efforts, we did not perform end-inspiratory holds to obtain quasi-static pressure measurements although some observations suggest that such measurements are feasible in the presence of inspiratory effort 
provided expiratory muscle activity is minimal [27, 28]. Consequently, $\Delta P_{\mathrm{L}, \mathrm{dyn}}$ as measured in this study represents a "dynamic" measure that may overestimate the actual mechanical stress applied to the lung during tidal ventilation. On the other hand, while $\Delta P_{\mathrm{L}}$ at the inspiratory plateau corresponds to the time of maximal alveolar distension in the non-dependent lung, peak $\Delta P_{\mathrm{L}, \mathrm{dyn}}$ is reached at the time point when dependent lung-the region most at risk during spontaneous breathing-is maximally distended by vigorous spontaneous efforts [3]. It may therefore be the more clinically relevant marker of dynamic lung stress in this context. Future studies should determine whether dynamic or quasi-static measurements of $\Delta \mathrm{P}_{\mathrm{L}}$ best reflect regional distending pressures.

Second, $P_{\text {mus }}$ measurements require measurement of elastic chest wall recoil pressure; owing to the absence of recordings of passive ventilation in most subjects, we relied on empirical estimates of chest wall elastance derived from predicted lung volumes. The reliability of this empiric approach is uncertain, but reassuringly, we found that predicted values of chest wall elastic recoil pressure approximated measured values in patients where direct measurements of chest wall elastance were available (as reported in the Additional file 1).

Third, the number of patients in the primary dataset $(n=$ 16) is relatively small, possibly limiting the generalizability of the validation findings. The study population is representative of a broad range of ventilated patients with acute hypoxemic respiratory failure. To avoid overfitting the predicted values of $k_{1}$ and $k_{2}$ to our dataset and to estimate the precision of our estimates of the limits of agreement, we employed a cross-validation technique. Importantly, the approach to detecting excessive $P_{\text {mus }}$ and $\Delta P_{\mathrm{L}, \mathrm{dyn}}$ from $\Delta P_{\text {occ }}$ performed extremely well in the independent external validation cohort from a different country (China). The generalizability of these findings is also supported by the fact that the value of $k_{1}$ estimated in this study (median 0.74 ) corresponds closely to the value estimated by Bellani et al. when they derived the $P_{\text {mus }}-E_{\mathrm{di}}$ index (0.66) in an Italian study [29].

\section{Clinical implications}

Regular measurements of $\Delta P_{\text {occ }}$ to estimate $P_{\text {mus }}$ and $\Delta P_{\mathrm{L}, \mathrm{dyn}}$ during mechanical ventilation provide a highly feasible means of detecting excessive respiratory effort and excessive dynamic lung stress directly from ventilator waveforms. Most modern ventilators have capacity to apply an end-expiratory occlusion during ventilation in controlled or partially assisted modes. $P_{\text {mus }}$ and $\Delta P_{\mathrm{L}, \mathrm{dyn}}$ values predicted from $\Delta P_{\text {occ }}$ are not sufficiently accurate to replace direct clinical monitoring (i.e., esophageal pressure) if desired by clinicians. Rather, these estimates could be used as a highly feasible, rapid, non-invasive "screening test" for excessive $P_{\text {mus }}$ and $\Delta P_{\mathrm{L}, \mathrm{dyn}}$. These data could be employed as an indication to deploy more direct monitoring techniques (i.e., esophageal manometry) or to guide adjustments to ventilator assist level, sedation, and opioids (Fig. 4). The maneuver was well-tolerated in our study.
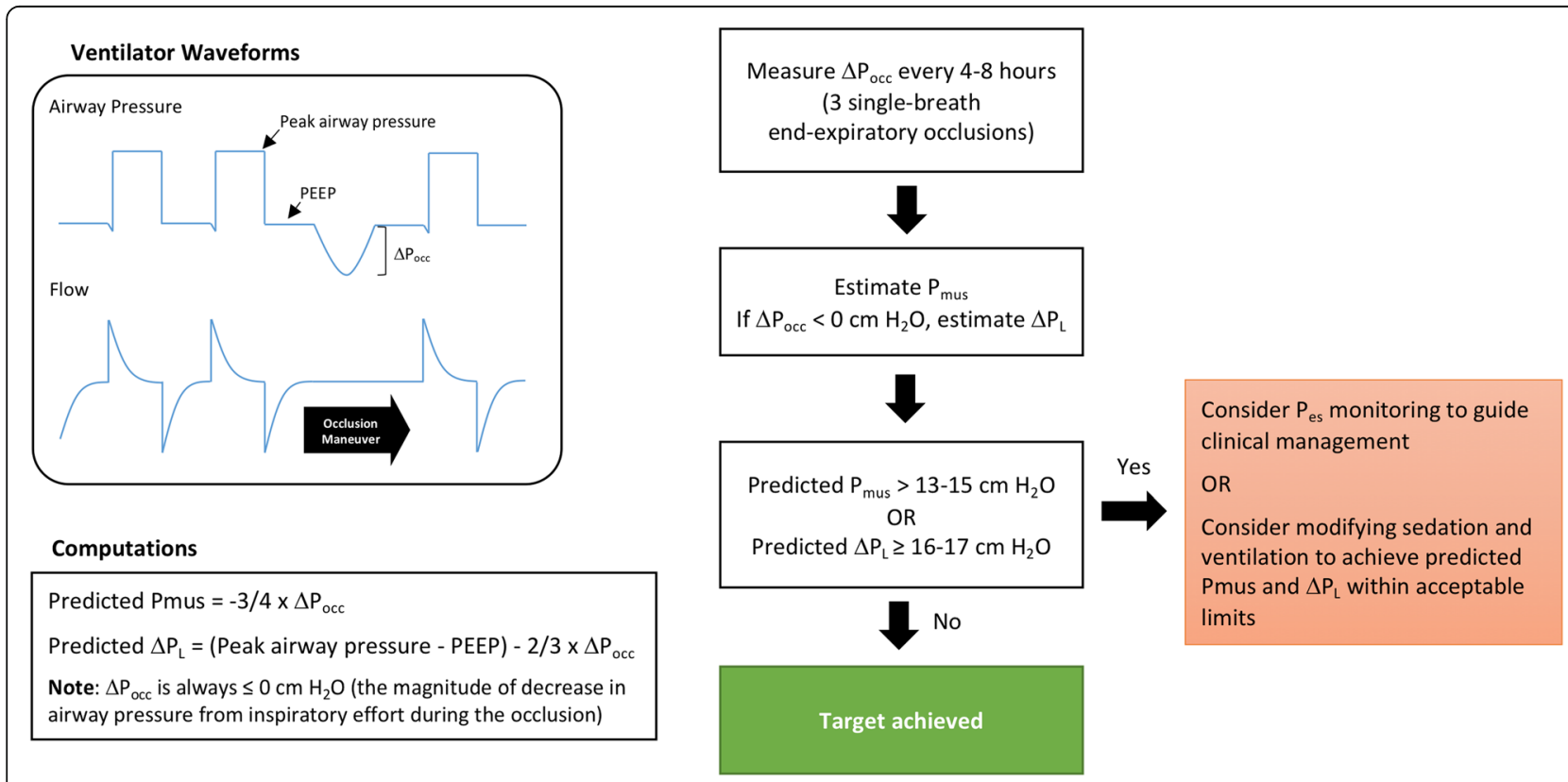

Fig. 4 Proposed clinical algorithm for monitoring respiratory muscle pressure $\left(P_{\text {mus }}\right)$ and dynamic transpulmonary pressure swings $\left(\Delta P_{L}\right)$ based on the negative deflection in airway pressure during an end-expiratory airway occlusion maneuver $\left(\Delta P_{\text {occ }}\right)$. $P_{\text {es, }}$, esophageal pressure 


\section{Conclusions}

Inspiratory effort and dynamic lung stress often exceed safe limits in patients breathing spontaneously under mechanical ventilation. The airway pressure deflection resulting from patient inspiratory effort during a transient end-expiratory occlusion maneuver $\left(\Delta P_{\text {occ }}\right)$ can be used to detect excessive (potentially injurious) inspiratory effort and dynamic lung stress.

\section{Supplementary information}

Supplementary information accompanies this paper at https://doi.org/10. 1186/s13054-019-2617-0

Additional file 1. Supplemental description of methods

Additional file 2: Figure S1. $\triangle$ Pocc is correlated with inspiratory effort quantified by the pressure-time product of Pmus.

Additional file 3: Figure S2. Accuracy of predicting Pmus and $\Delta P_{L}$ from $\Delta$ Pocc assessed by Bland-Altman plots.

Additional file 4: Table S1. Agreement between measured and predicted Pmus and $\Delta P_{L}$

Additional file 5: Table S2. Discriminative performance of predicted

Pmus and $\Delta P_{L}$ values to detect excessive Pmus and $\Delta P_{L}$.

\section{Abbreviations}

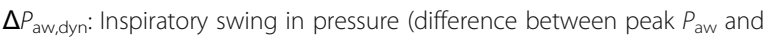
$P E E P$ ); $\Delta P_{L, \text { dyn }}$ : Dynamic transpulmonary driving pressure; increase in $P_{L}$ from onset to peak during inspiration; $\Delta P_{\mathrm{L}, \text { dyn }}$ : Dynamic transpulmonary driving pressure swing from end-expiration to peak transpulmonary pressure; $\Delta P_{\text {occ: }}$ : Airway pressure deflection generated by the patient's respiratory effort against the occluded airway; airway pressure from PEEP. The time of occlusion is as long as the duration of a single breath; $E_{\mathrm{di}}$ : Diaphragm electrical activity; $k_{1}$ : The ratio of mean $P_{\text {mus }}$ (during all non-occluded breaths) to the mean $\Delta P_{\text {occ }}\left(k_{1}=P_{\text {mus }} / \Delta P_{\text {occ }}\right) ; k_{2}$ : The ratio of mean $\Delta P_{\text {es }}$ (during all non-occluded breaths) to the mean $\Delta P_{\text {occ }}\left(k_{2}=\Delta P_{\text {es }} / \Delta P_{\text {occ }}\right)$; $P_{0.1}$ : The airway occlusion pressure at 100 milliseconds after the onset of inspiration; $P_{\text {aw: }}$ : Airway pressure; $P_{c w}$ : Chest wall elastic recoil pressure at end-inspiration; $P_{\text {es: }}$ : Esophageal pressure; $P_{\perp}$ : Transpulmonary pressure: $P_{\text {mus: }}$ : Respiratory muscle pressure (inspiratory effort); peak difference between $P_{c w}$ and $P_{\text {es }}$ during inspiration; PTP $_{\text {mus }}$ : Pressure-time product of $P_{\text {mus }}$ per breath; SAS score: Sedation-Agitation Scale score; SOFA score: Sequential Organ Failure Assessment score

\section{Authors' contributions}

The study was conceived by MB and EG. Measurements were collected by EG. Signal analysis was conducted by MB and EG. Statistical analysis was conducted by EG. MB and EG drafted the manuscript. All authors critically revised the manuscript for important intellectual content. All authors read and approved the final manuscript.

\section{Funding}

This research was sponsored by PSI Foundation. Dr. Goligher is supported by an Early Career Investigator Award from the Canadian Institutes of Health Research. Dr. Fan is supported by a New Investigator Award from the Canadian Institutes of Health Research. The funders played no role in the design, analysis, or reporting of the results. The authors have no financial relationship with the organizations that funded the research.

\section{Availability of data and materials}

The datasets generated and/or analyzed during the current study are not publicly available due to ongoing analysis in the primary study but are available from the corresponding author on reasonable request.

\section{Ethics approval and consent to participate}

Approval for the study procedures and data collected for this report was obtained from the research ethics board at the University Health Network (12-5582).

\section{Consent for publication}

Not applicable.

\section{Competing interests}

Dr. Goligher's laboratory receives support in the form of equipment from Getinge, and Dr. Goligher has received speaking honoraria from Getinge. The other authors declare that they have no competing interests.

\section{Author details}

${ }^{1}$ Department of Anesthesia, Critical Care and Emergency, Spedali Civili di Brescia, University of Brescia, UNIBS, Brescia, Italy. ${ }^{2}$ Department of Medical and Surgical Specialities, Radiological Sciences and Public Health, University of Brescia, UNIBS, Brescia, Italy. ${ }^{3}$ Interdepartmental Division of Critical Care Medicine, University of Toronto, Toronto, Canada. ${ }^{4}$ Keenan Centre for Biomedical Research, Li Ka Shing Knowledge Institute, St. Michael's Hospital, Toronto, Canada. ${ }^{5}$ Division of Respirology, Department of Medicine, University Health Network and University of Toronto, Toronto, Canada. ${ }^{6}$ Respiratory Therapy, University Health Network, Toronto, Canada. ${ }^{7}$ Institute for Health Policy, Management, and Evaluation, University of Toronto, Toronto, Canada. ${ }^{8}$ Department of Critical Care Medicine, Zhongda Hospital, Southeast University, Nanjing, China. ${ }^{9}$ Department of Physiology, University of Toronto, Toronto, Canada. ${ }^{10}$ Toronto General Hospital Research Institute, Toronto, Canada. ${ }^{11}$ Toronto General Hospital, 585 University Ave., Peter Munk Building, 11th Floor, Room 192, Toronto, ON M5G 2N2, Canada.

Received: 5 July 2019 Accepted: 20 September 2019

Published online: 06 November 2019

\section{References}

1. Yoshida T, Nakahashi S, Nakamura M, Koyama Y, Roldan R, Torsani V, et al. Volume-controlled ventilation does not prevent injurious inflation during spontaneous effort. Am J Resp Crit Care. 2017;196:590-601.

2. Papazian L, Forel J-M, Gacouin A, Penot-Ragon C, Perrin G, Loundou A, et al. Neuromuscular blockers in early acute respiratory distress syndrome. New Engl J Medicine. 2010;363:1107-16.

3. Yoshida T, Amato MB, Kavanagh BP. Understanding spontaneous vs ventilator breaths: impact and monitoring. Intens Care Med. 2018;164:43.

4. Orozco-Levi M, Lloreta J, Minguella J, Serrano S, Broquetas J, Gea J. Injury of the human diaphragm associated with exertion and chronic obstructive pulmonary disease. Am J Resp Crit Care. 2001;164:1734-9.

5. Hussain S, Roussos C. Distribution of respiratory muscle and organ blood flow during endotoxic shock in dogs. J Appl Physiol. 1985;59:1802-8.

6. Goligher EC, Dres M, Fan E, Rubenfeld GD, Scales DC, Herridge MS, et al. Mechanical ventilation-induced diaphragm atrophy strongly impacts clinical outcomes. Am J Resp Crit Care. 2018;197:204-13.

7. Vaporidi K, Akoumianaki E, Telias I, Goligher EC, Brochard L, Georgopoulos D. Respiratory drive in critically ill patients: pathophysiology and clinical implications. Am J Respir Crit Care Med 2019:0.

8. Gentzler ER, Derry H, Ouyang DJ, Lief L, Berlin DA, Xu C, et al. Underdetection and undertreatment of dyspnea in critically ill patients. Am J Resp Crit Care. 2019;199:1377-1384.

9. Mauri T, Yoshida T, Bellani G, Goligher EC, Carteaux G, Rittayamai N, et al. Esophageal and transpulmonary pressure in the clinical setting: meaning, usefulness and perspectives. Intens Care Med. 2016;42:1360-73.

10. Beck J, Gottfried SB, Navalesi P, Skrobik Y, Comtois N, ROSSINI M, et al. Electrical activity of the diaphragm during pressure support ventilation in acute respiratory failure. Am J Resp Crit Care. 2001;164:419-24.

11. Goligher EC, Laghi F, Detsky ME, Farias P, Murray A, Brace D, et al. Measuring diaphragm thickness with ultrasound in mechanically ventilated patients: feasibility, reproducibility and validity. Intens Care Med. 2015:41:734.

12. Telias I, Damiani F, Brochard L. The airway occlusion pressure (P0.1) to monitor respiratory drive during mechanical ventilation: increasing awareness of a not-so-new problem. Intens Care Med. 2018;195:438-4.

13. Amato MB, Meade MO, Slutsky AS, Brochard L, Costa EL, Schoenfeld DA, et al. Driving pressure and survival in the acute respiratory distress syndrome. New Engl J Med. 2015;372:747-55.

14. Bellani G, Grasselli G, Teggia-Droghi M, Mauri T, Coppadoro A, Brochard L, et al. Do spontaneous and mechanical breathing have similar effects on average transpulmonary and alveolar pressure? A clinical crossover study. Crit Care. 2016;20:142. 
15. Xirouhaki N, Kondili E, Mitrouska I, Siafakas N, Georgopoulos D. Response of respiratory motor output to varying pressure in mechanically ventilated patients. Eur Respiratory J. 1999;14:508-16.

16. Liu L, Liu S, Xie J, Yang Y, Slutsky AS, Beck J, et al. Assessment of patientventilator breath contribution during neurally adjusted ventilatory assist in patients with acute respiratory failure. Crit Care. 2015;19:43.

17. Jubran A, Tobin M. Pathophysiologic basis of acute respiratory distress in patients who fail a trial of weaning from mechanical ventilation. Am J Resp Crit Care. 1997;155:906-15

18. Carteaux G, Mancebo J, Mercat A, Dellamonica J, Richard J-CM, AguirreBermeo $\mathrm{H}$, et al. Bedside adjustment of proportional assist ventilation to target a predefined range of respiratory effort. Crit Care Med. 2013; 41:2125-32.

19. Mancebo J, Isabey D, Lorino H, Lofaso F, Lemaire F, Brochard L. Comparative effects of pressure support ventilation and intermittent positive pressure breathing (IPPB) in non-intubated healthy subjects. Eur Respir J. 1995:8:1901-9.

20. Jubran A, Grant BJ, Laghi F, Parthasarathy S, Tobin MJ. Weaning prediction: esophageal pressure monitoring complements readiness testing. Am J Resp Crit Care. 2005;171:1252 1259

21. Myles $P, C U I J$ J. Using the Bland-Altman method to measure agreement with repeated measures. Bja Br J Anaesth. 2007:99:309-11.

22. Euser AM, Dekker FW, le Cessie S. A practical approach to Bland-Altman plots and variation coefficients for log transformed variables. I Clin Epidemiol. 2008;61:978-82.

23. Altman DG, Royston P. What do we mean by validating a prognostic model? Stat Med. 2000;19:453-73.

24. Grassino A, Goldman, Mead J, Sears T. Mechanics of the human diaphragm during voluntary contraction: statics. J Appl Physiol. 1978;44:829-39.

25. Goldman GA, Mead J, Sears T. Mechanics of the human diaphragm during voluntary contraction: dynamics. J Appl Physiol. 1978;44:840-8.

26. Brochard L, Slutsky A, Pesenti A. Mechanical ventilation to minimize progression of lung injury in acute respiratory failure. Am J Resp Crit Care. 2017;195:438-42.

27. Bellani G, Grassi A, Sosio S, Gatti S, Kavanagh BP, Pesenti A, et al. Driving pressure is associated with outcome during assisted ventilation in acute respiratory distress syndrome. Anesthesiology. 2019:131:594-604.

28. Bellani G, Grassi A, Sosio S, Foti G. Plateau and driving pressure in the presence of spontaneous breathing. Intens Care Med. 2019:45:97-8

29. Bellani G, Mauri T, Coppadoro A, Grasselli G, Patroniti N, Spadaro S, et al. Estimation of patient's inspiratory effort from the electrical activity of the diaphragm. Crit Care Med. 2013;41:1483-91.

\section{Publisher's Note}

Springer Nature remains neutral with regard to jurisdictional claims in published maps and institutional affiliations.

Ready to submit your research? Choose BMC and benefit from:

- fast, convenient online submission

- thorough peer review by experienced researchers in your field

- rapid publication on acceptance

- support for research data, including large and complex data types

- gold Open Access which fosters wider collaboration and increased citations

- maximum visibility for your research: over $100 \mathrm{M}$ website views per year

At $\mathrm{BMC}$, research is always in progress.

Learn more biomedcentral.com/submissions 